\title{
ESTUDIO PRELIMINAR SOBRE LAS ANFORAS ROMANAS DEL PORTUS ILLICITANUS
}

\author{
M. ${ }^{a}$ JOSE SANCHEZ FERNANDEZ \\ y M. ${ }^{\mathrm{a}}$ TERESA LOBREGAD COLLADO \\ Museo Arqueológico de Santa Pola (Alicante)
}

\begin{abstract}
En este trabajo se anticipan algunos datos, referidos al estudio de un grupo significativo, que forma parte de un amplio conjunto de ánforas halladas en el curso de las últimas campañas de excavaciones (1982-83) realizadas en el Portus Illicitanus.

Se trata de un material que presenta una extensa cronología (siglos I al V), con unas formas representadas en la tipología de Dressel, que abarcan las familias Dr. 2-4 de asa bífida para transporte de vino; Dr. 7-11 destinadas al transporte de salsas de pescado, olearias Dr. 20, africanas y Almagro 51 entre otras, como formas más representativas numéricamente. Su estudio y clasificación permiten obtener los primeros datos sobre el tráfico marítimo mediterráneo de este sector costero, en época romana, así como su incidencia en el comercio de la época.
\end{abstract}

Ce travail avance quelques reférences aux études d'un groupe significatif formant partie d'un ensemble d'amphores trouvées pendant les dernières fouilles (1982-83) effectués auprès de Portus Illicitanus.

Il s'agit de matériaux appartenant à une cronologie assez vaste (siècles I-V) et des formes représentées par la typologie de Dressel, aparaissant les familles Dr. 2-4 d'anse bifide pour le transport du vin; Dr. 7-11 destinées au transport de sauces de poissons; oléacées Dr. 20, africaines et Almagro 51, parmi d'autres, comme formes plus abondantes. Leur étude et clasification nous permet d'obtenir les prémiers rapport de données sur le trafic maritime mediterranéen de ce secteur côtier à l'époque romaine, et même leur incidence auprès du commerce à ce temps-là.

Este trabajo tiene por objeto estudiar y dar a conocer una parte representativa de un gran lote de ánforas halladas en las excavaciones del Portus Illicitanus de Santa Pola, durante las últimas campañas realizadas en 1982-83 (1).

Hemos procedido a iniciar su estudio a partir de una muestra representativa de los distintos tipos, en base a la inmensa cantidad de recipientes anfóricos que componen mayoritariamente los distintos niveles de las excavaciones, y que confirma la actividad comercial desarrollada en el Portus Illicitanus durante la época romana a través del tráfico marítimo mediterráneo.

Para su clasificación hemos seguido básicamente la tabla tipológica de Dressel, así como diversos paralelos procedentes de otros yacimientos cronológicamente bien data-

(1) La totalidad de lạs ánforas aparecidas hasta el momento son objeto del estudio iniciado por M. T. Lobregad Collado, en lo que constituirá su tesis de licenciatura, dirigida por el profesor Abad Casal. 
dos. Es preciso señalar el estado de excesiva fragmentación que presenta el material en general, y por tanto la carencia de piezas completas, tratándose a lo sumo de bordes, cuellos, asas sueltas, o en el mejor de los casos del tercio superior del ánfora, lo cual, a menudo, dificulta la clasificación.

Por otra parte, nos encontramos en las excavaciones con algunos sectores donde el terreno ha sido removido a causa de labores agrícolas, rebaje para construcciones, etc., lo cual ha dado lugar a una alteración estratigráfica y a la consiguiente mezcla de materiales de diferente cronología.

Las conclusiones obtenidas en este trabajo se verán complementadas o sujetas a modificación, una vez concluido el estudio del resto de materiales hallados en estas excavaciones (2).

Los envases que aquí presentamos proceden de tres zonas distintas:

a) Plaza de los Aljibes

b) Avenida del Portus Illicitanus

c) Parque «El Palmeral» (fig. 4).

\section{a) Plaza de los Aljibes}

De los trabajos realizados en dicha zona ya dimos noticia con anterioridad al estudiar las cerámicas comunes del Portus Illicitanus (SANCHEZ, 1983). Es preciso destacar que los fragmentos de ánforas procedentes de dicha excavación carecen de contexto arqueológico por formar parte del relleno de unas balsas.

\section{b) Avenida del Portus Ilicitanus}

Las excavaciones en esta zona dieron comienzo en marzo de 1982, con carácter de urgencia, a raíz de la inminente construcción de un bloque de viviendas. Los trabajos fueron realizados a cargo del Museo Provincial de Alicante, bajo la dirección de don Enrique Llobregat Conesa. Aquí pudimos constatar que los niveles tardíos, correspondientes a los siglos IV y V, se hallaban completamente arrasados, como consecuencia de los desmontes del terreno que años atrás se llevaron a cabo para construir la carretera y allanar los alrededores. El hallazgo de unas construcciones rectangulares, con un gran número de fragmentos de ánforas en su interior, nos hace suponer que se trata de almacenes para depositar temporalmente las mercancías procedentes de otros lugares del imperio.

El área excavada hasta este momento presenta una superficie de $1.100 \mathrm{~m} .^{2} \mathrm{y}$ muestra dos niveles: en el primero aparece una capa de relleno, compuesta por una tierra muy suelta de color grisáceo, con mezcla de arena muy fina y materiales actuales. A partir de los $30 \mathrm{~cm}$. de profundidad, la tierra cambia de color y consistencia y aparecen estructuras arquitectónicas y materiales correspondientes al siglo III, de los cuales hay que destacar una gran cantidad de cerámicas africanas: Terra Sigillata Clara, ánforas y vasijas de cocina, junto a Terra Sigillata Hispánica tardía y cerámica común.

En un segundo nivel, compuesto de varias capas de cenizas y tierra ocre arenosa, se constata la presencia de materiales anfóricos correspondientes a los siglos I y II, junto a terra sigillata aretina y sudgálica, lucernas de volutas, paredes finas y abundante cerámica común, aunque los resultados definitivos para su datación se hallan pendientes de un estudio de conjunto del resto de materiales mencionados.

(2) El material procedente de las últimas campañas de excavaciones en el Portus Illicitanus está siendo estudiado en la actualidad por quienes suscriben este trabajo en colaboración con Elena Blasco Martínez y Araceli Guardiola Martínez, en el Museo Arqueológico Municipal de Santa Pola, en lo que constituirá la Memoria Científica de Excavaciones, de próxima publicación. 


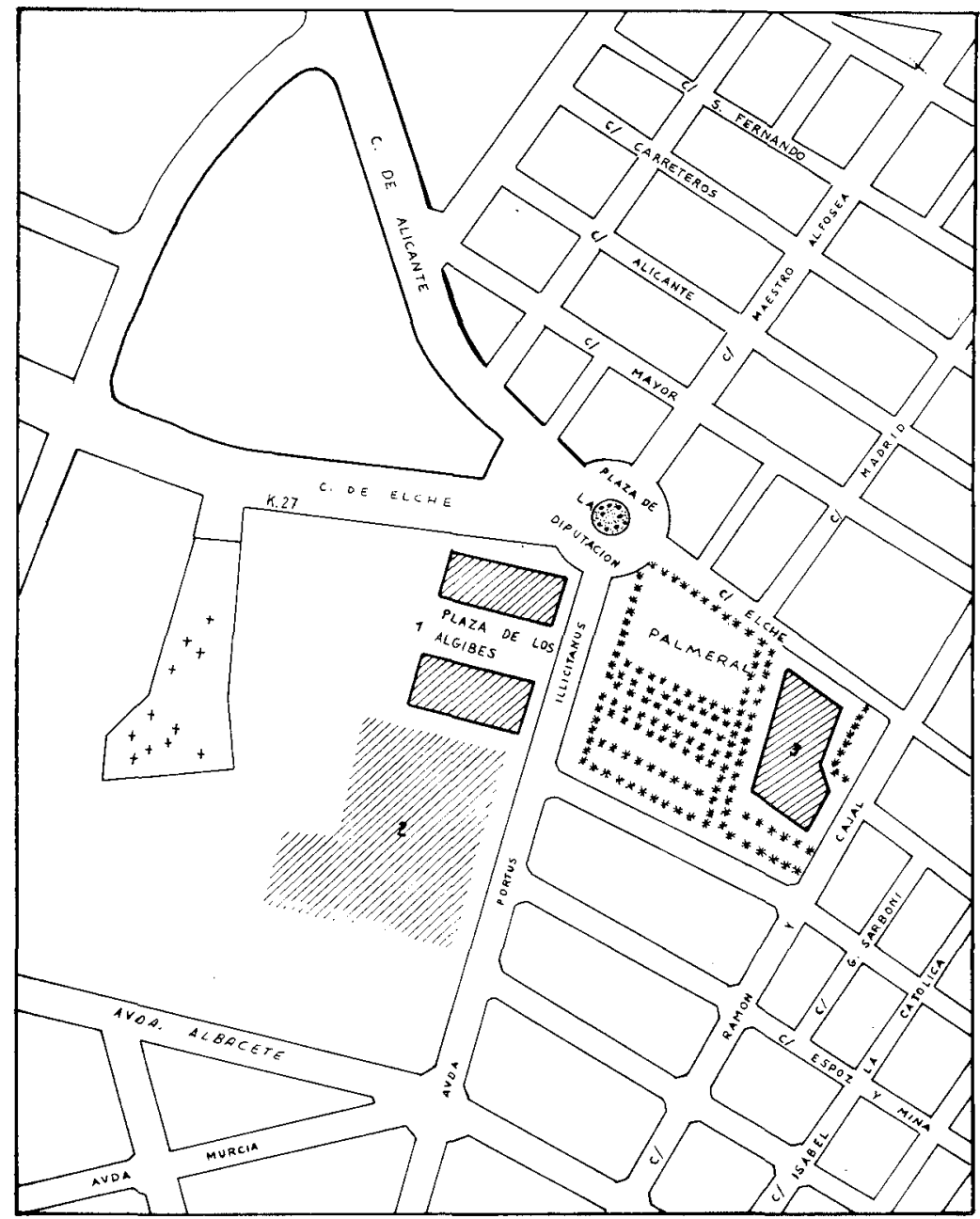

Fig. 1. Plano de Santa Pola. Localización de los hallazgos

La ausencia de ánforas de cronología anterior al siglo I de la Era se debe, fundamentalmente, al hecho de no haber proseguido la excavación en esta zona, profundizando hasta niveles más antiguos, tarea que dejamos para futuras campañas, de las cuales esperamos obtener un repertorio más amplio en lo que a ánforas se refiere y que vendrán a completar el panorama que en este estudio presentamos.

\section{c) Parque «EI Palmeral»}

En julio de 1983, a raíz de la construcción de una fuente en el parque público «El Palmeral», se procedió a realizar un sondeo de urgencia, el cual dio como resultado el hallazgo de un mosaico. En octubre del mismo año se excavó la zona, saliendo a la luz una casa con peristilo, que rodea un patio central de $14 \mathrm{~m}$. de lado y varias estancias a su alrededor. El pavimento de dicha casa se halla a la profundidad de un metro. En este nivel se han hallado materiales tardíos, fechables a lo largo del siglo IV, entre los cuales se observa un claro predominio de recipientes de procedencia africana.

A partir de un metro de profundidad, por debajo del pavimento, aparece una tierra de color grisáceo, compacta y con grandes manchas de cenizas. En este nivel abundan 
los fragmentos de ánforas, así como la terra sigillata clara, terra sigillata hispánica tardía y monedas del Bajo Imperio, materiales fechables todos ellos en la segunda mitad del siglo III.

\section{ANFORAS VINARIAS TIPO Dr. 2-4 (Figs. 2, 3)}

Desde el siglo I a. C., hasta comienzos del siglo II d. C., se fabrican en el Lacio y la Campania ánforas Dr. 2-4, utilizándose como envase para los vinos itálicos, según muestran los tituli picti. Se las puede considerar como una derivación de las ánforas greco-itálicas, con gran auge en la época de Augusto, en la que reemplazan a la Dr. 1, siendo imitadas en otros puntos del Mediterráneo occidental, entre los que destacan los talleres de la Tarraconense y la Bética (ENGUIX y ARANEGUI, 1977, 27).

La forma del labio varía, encontrando dentro del mismo tipo labios engrosados de sección redondeada, de sección triangular pendiente, o rectos ligeramente engrosados. La amplitud de la boca es de una media de $14 \mathrm{~cm}$. El cuello suele ser troncocónico o cilíndrico, con asas bífidas de sección redondeada que parten por debajo del labio.

El origen itálico o tarraconense de este tipo de recipientes se establece en base a la composición de la pasta como único criterio diferenciador (TCHERNIA y ZEVI, 1972, 37).

Los ejemplares que poseemos de la familia Dr. 2-4 posiblemente provienen de la Tarraconense. Estas ánforas han sido objeto de un estudio muy completo por parte de varios autores (TCHERNIA, 1972; FERNANDEZ IZQUIERDO, 1980; ARANEGUI, 1977; BELTRAN, 1970; NOLLA, 1974), los cuales atribuyen su origen a la Tarraconense. Se trata de tipos que imitan los itálicos, extendiéndose su producción por toda esta provincia romana, sin tener un tipo preestablecido, si bien presentan dos tipos de arcilla, correspondientes a dos centros diferentes de producción (FERNANDEZ IZQUIERDO, 1980, 176). En el primer caso la pasta es de color rojo-amarronado, poco depura$\mathrm{da}$, porosa y de textura muy basta, con abundante desengrasante de gruesos granos
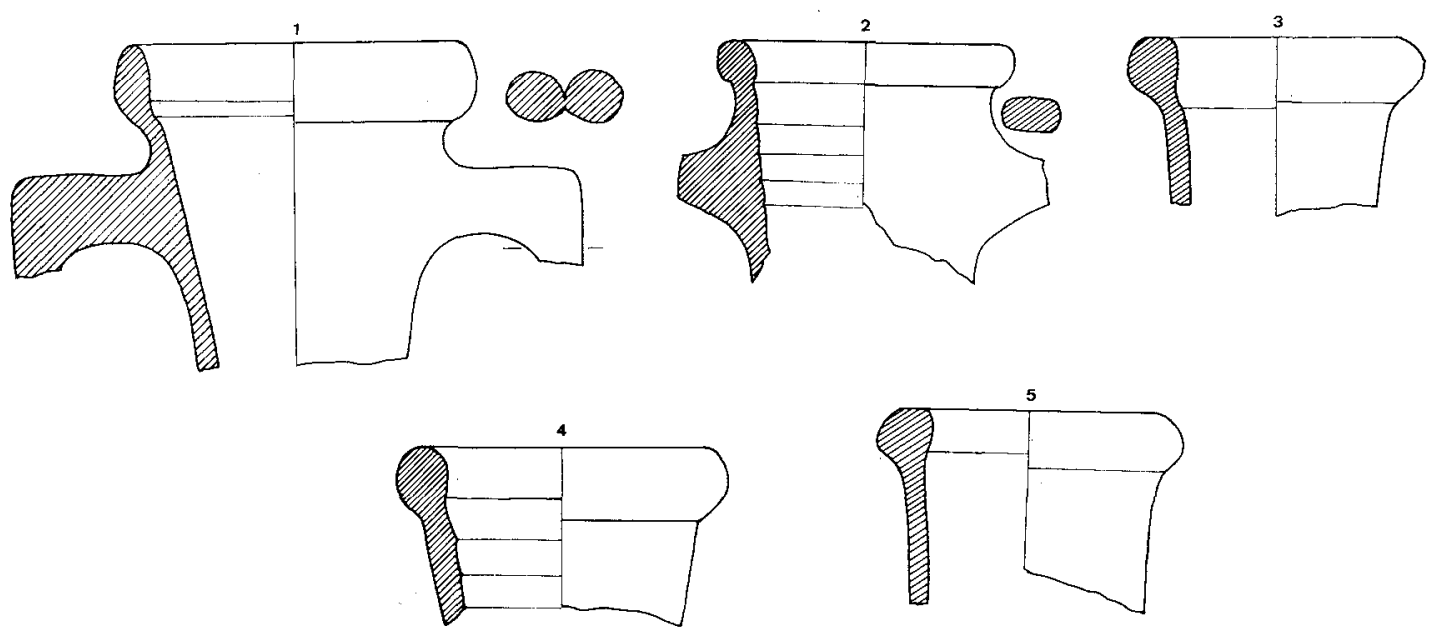

o

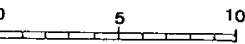

Fig. 2. Anforas vinarias del tipo Dr. 2-4 

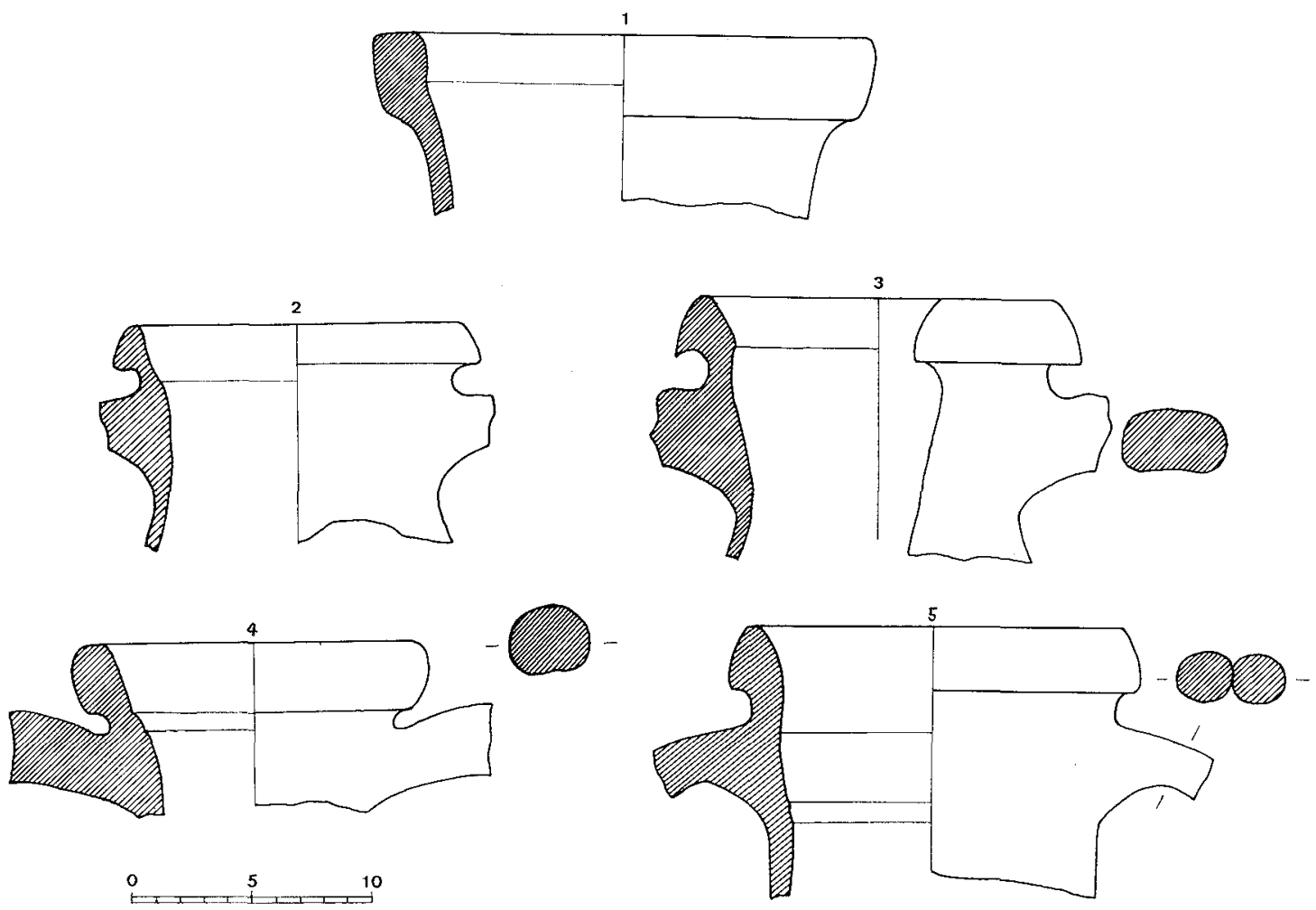

Fig. 3. Anforas vinarias del tipo Dr. 2-4

blancos de cuarzo. En ningún caso la superficie exterior se recubre con engobe. En las paredes internas del cuello se aprecia una serie de estrías.

Por otra parte, contamos con otros recipientes que presentan una pasta de color ocre-rosáceo, con desengrasante poco visible de escasos puntos blancos, en cuyas paredes exteriores se aprecian restos de engobe de color crema claro.

Las ánforas Dr. 2-4 del Portus Illicitanus, aparecen en un nivel estratigráfico altoimperial, sin que por el momento sea posible establecer una evolución de los tipos, hasta que esté concluido el estudio del resto de los materiales correspondientes a la excavación.

Para establecer el período de vigencia de las ánforas Dr. 2-4 contamos con estudios generales, entre ellos el de Zevi (ZEVI, 1966), que se centra en las fechas consulares encontradas en los títuli picti del yacimiento próximo al Castro Pretorio, datado en la primera mitad del siglo I d. C., y el de Tchernia y Zevi (TCHERNIA y ZEVI, 1972), que establecen la posibilidad de distinguir grupos de ánforas Dr. 2-4 de distinto origen, a través del estudio de las pastas, teniendo en cuenta su distribución en las estratigrafías de la Casa de las Paredes Amarillas y de las Termas de Neptuno de Ostia, donde siempre aparecen entre Tiberio y los Flavios.

Están presentes en el comercio mediterráneo desde el principado de Augusto, hasta el siglo II (ZEVI, 1966, 208). Aparecen en Ostia, constituyendo la forma L I (PANELLA, 1970, 102); se imitan en la Tarraconense (TCHERNIA y ZEVI, 1972, 35; ENGUIX y ARANEGUI, 1977, 30; TCHERNIA, 1971, 33), en la Bética (BELTRAN, 1974, 112 y ss.,), en la Gallia Narbonense (LABENHEINER y WIDEMANN, 1977, 80), e incluso en Africa (FERNANDEZ IZQUIERDO, 1980, 140) y en el Limes Germánico (TCHERNIA, 1972, 62). 


\section{ANFORAS PARA SALSAS TIPO Dr. 7-11 (Figs. 4-5)}

Los textos antiguos ya nos hablan de la elaboración de salazones en España, en época prerromana, según noticias de Eupolis Antífanes. Autores latinos como Plinio (N. H. XXXII, 146) y Marcial (VII, 7, 8) mencionan en su obra la importancia de dicho producto. Sin embargo, la gran difusión de este tipo de envases se produce con el cambio de era, durante el reinado de Augusto, perdurando a lo largo de todo el siglo II, y tal vez algunos decenios más (BELTRAN, 1977, 100).

Dieciséis fragmentos de boca, pertenecientes a la familia Dr. 7-11, hallados en el Portus Illicitanus, reproducen el tipo de ánforas para salsas de pescado propias de los talleres hispánicos. Dentro de esta familia, se aprecian ostensibles diferencias en la tipología, por lo que hemos procedido a su clasificación estableciendo dos grupos:

a) De labio exvasado moldurado, con un diámetro que alcanza la media de $19,5 \mathrm{~cm}$. (fig. 4).

b) De boca en forma de campana invertida, con un diámetro alrededor de los $14 \mathrm{~cm}$. Estas dimensiones menores que las del grupo anterior nos inducen a incluirlas dentro del tipo Dr. 8 (fig. 5).

El primer grupo presenta un labio ligeramente engrosado, exvasado y con moldura, cuello largo troncocónico y asas de sección oval surcadas por una profunda estría. La pasta suele ser de color ocre-rosáceo o rojizo, basta, porosa, poco depurada, con abundante desengrasante de puntos negros y superficie exterior recubierta por un engobe blanquecino de tacto rugoso, que en ocasiones se prolonga hacia el interior del labio.

El gran número de variantes dificulta el poder precisar su evolución tipológica, ya que conviven desde época augustea hasta finales del siglo II, a través de formas completamente distintas. Las formas más antiguas proceden de Oberaden, datadas antes del fin del reinado de Augusto, con el cuello poco desarrollado y perfil del labio recto y sin molduras (BELTRAN, 1970, 392).

Durante la primera mitad del siglo I los labios presentan un perfil sencillo en forma de campana, sin molduras, en la mayoría de los casos. A partir de la época de Claudio el borde se hace más exvasado, con molduras en la parte inferior de la boca, que son los que más abundan (ARANEGUI, 1978, 313).

Los centros de producción más conocidos se localizan en la Bética (GIMENEZ DE CISNEROS, 1958, 469; SOTOMAYOR, 1969, 389; PEMAN, 1959, 169), citados por Beltrán (BELTRAN, 1970, 388 y ss.). La divulgación de estas ánforas por el Mediterráneo occidental comienza a partir del siglo I a. C. (ZEVI, 1966, 229 y ss.) y en Ostia se encuentran desde la época tardoaugustea hasta fines del siglo I d. C., formando el tipo LII de dicha localidad (PANELLA, 1970, 121).

Su expansión tiene lugar en todo el litoral mediterráneo: Ampurias, Sagunto, Valencia, Portus Illicitanus, Cartagena y en general por toda la Bética (BELTRAN, 1970, 406 y ss.). También fuera de la Península esta forma alcanzó gran expansión, documentándose restos de este tipo en Italia, en la Gallia y en el Norte de Africa (BELTRAN, 1970,412 y ss.).

\section{ANFORAS OLEARIAS DEL TIPO Dr. 20 (Fig. 6)}

Sólo contamos con tres bordes engrosados al exterior, de sección triangular, y varias asas robustas de sección circular atribuibles al tipo Dr. 20 de ánforas olearias.

La pasta es de color ocre, de textura muy basta, con abundante desengrasante de puntos negros finos y brillantes. Al carecer de más datos, debido a la escasez y a la fragmentación de este material, no podemos establecer una cronología aproximada. 

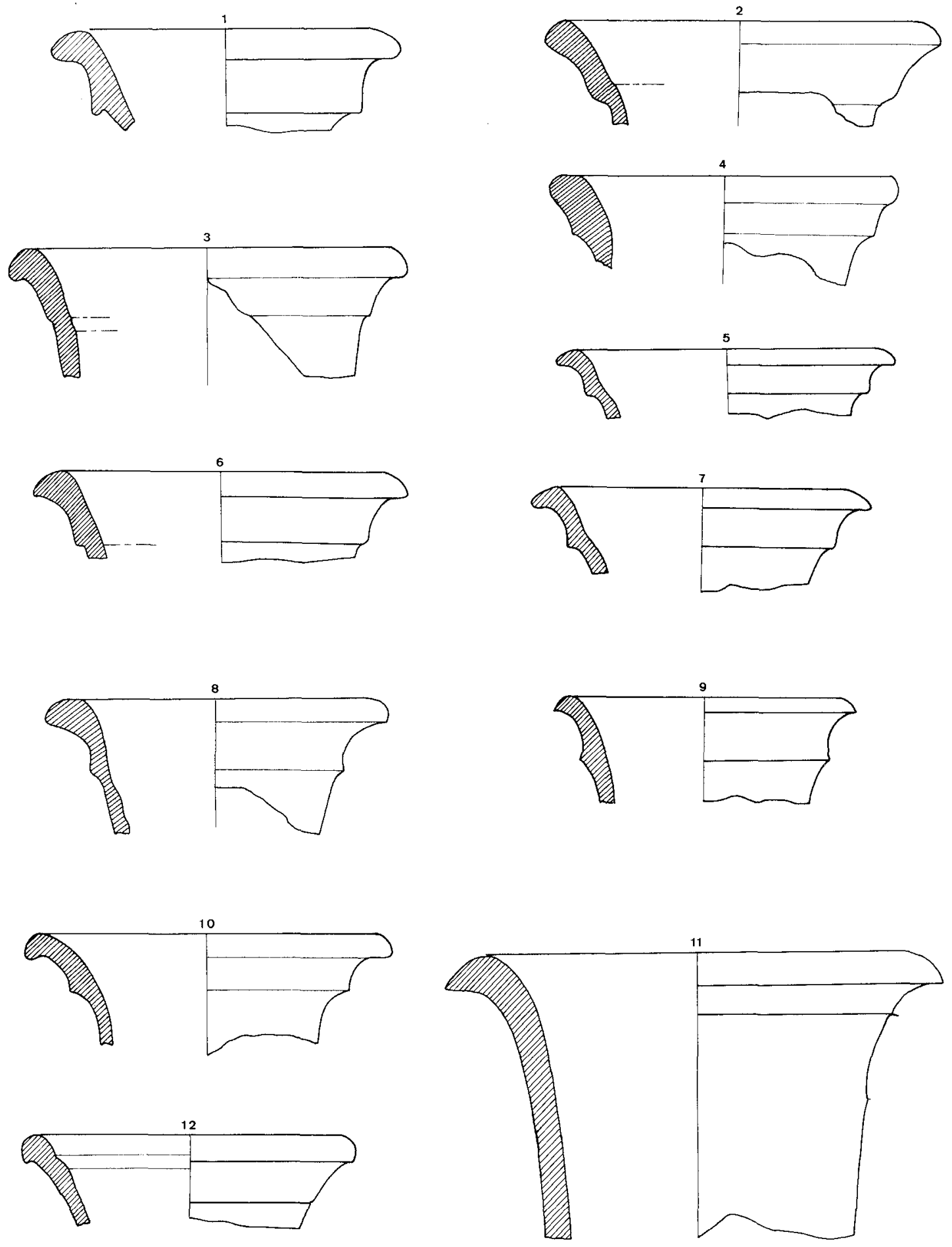

$\stackrel{0}{6}+5+10^{10}$

Fig. 4. Anforas para salsas del tipo Dr. 7-11 

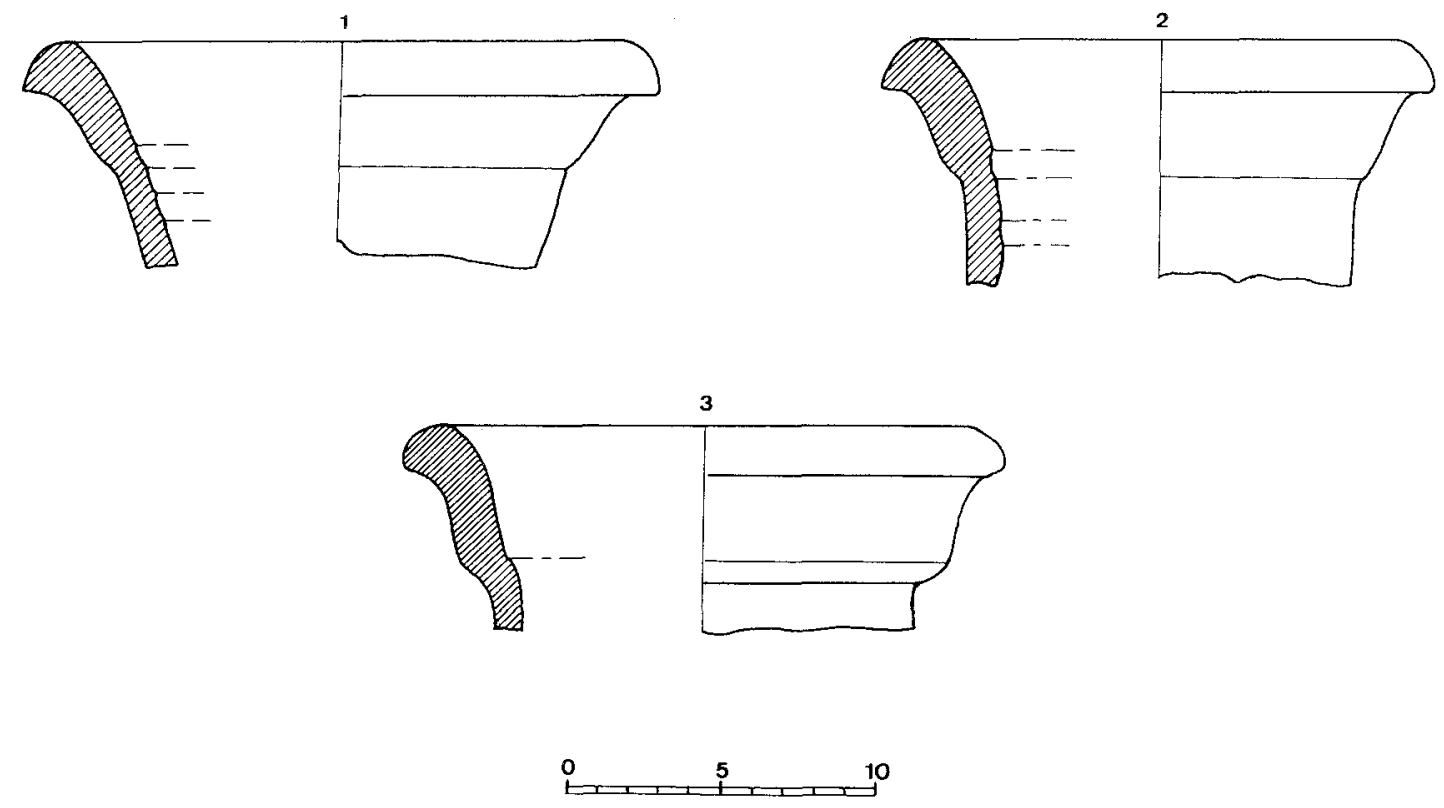

Fig. 5. Anforas para salsas del tipo Dr. 8

Cinco de estas asas ostentan marcas estampilladas, y otra marca de las mismas características se halla sobre un fragmento informe, posiblemente correspondiente a la panza. Todas estas marcas tienen en común las letras en relieve, en cartela de forma rectangular, correspondientes a las iniciales de los tria nomina y en ocasiones van separadas por puntos triangulares. Este sistema de marcas es propio de las ánforas de época altoimperial, datables en los siglos I y II (REMESAL, 1977, 93).

Las estampillas aparecidas son las siguientes:

$$
\begin{aligned}
& \text { N. }{ }^{\circ} 6 \text { - C N O V... } \\
& \text { N. } 4 \text { - L.P.M. } \\
& \text { N. } 5 \text { - M.P.F. } \\
& \text { N. } 8 \text { - P A L I S C A C } \\
& \text { N. } 7 \text { - G T } 22 \\
& \text { N. } 9 \text { - B V R B }
\end{aligned}
$$

La n. ${ }^{\circ} 6$ está reseñada por Callender (CALLENDER, 1965, 90) con el n. ${ }^{\circ} 408$, y se desarrolla $\mathrm{C} \mathrm{N} \mathrm{O} \mathrm{V} \mathrm{/} \mathrm{1.} \mathrm{La} \mathrm{segunda} \mathrm{(n.}{ }^{\circ} 4$ ) se encuentra en Callender con el n. ${ }^{\circ} 914$, si bien el facsímil (fig. 933) no reproduce exactamente la marca del Portus Illicitanus, cuyo desarrollo es L P ( ) M ( ) /servus/ ? Se puede considerar originaria del Sur de España, datable en el siglo II (CALLENDER, 1965, 163). La tercera $\left(n .^{\circ}\right.$ 5) corresponde al n. ${ }^{\circ} 35$ (fig. 11, 58-a) y se desarrolla (M.P. ( ) F ( )?). Los números 7, 8 y 9 no han sido localizados en los Corpus de Inscripciones ni en la bibliografia consultada al respecto (3).

(3) La mayor densidad de hallazgos del tipo Dr. 20 proceden del mar, recuperadas por las barcas de pesca, las cuales forman parte del Museo Municipal de Santa Pola. En la actualidad están siendo objeto de estudio por A. Fernández Izquierdo y M. J. Sánchez Fernández. 


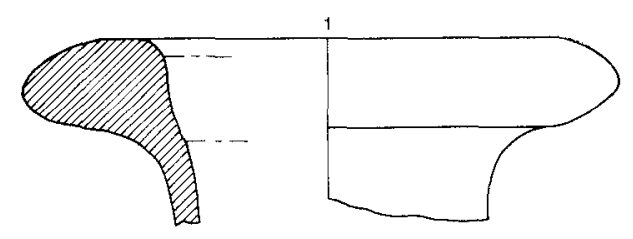

\section{[FPA]}
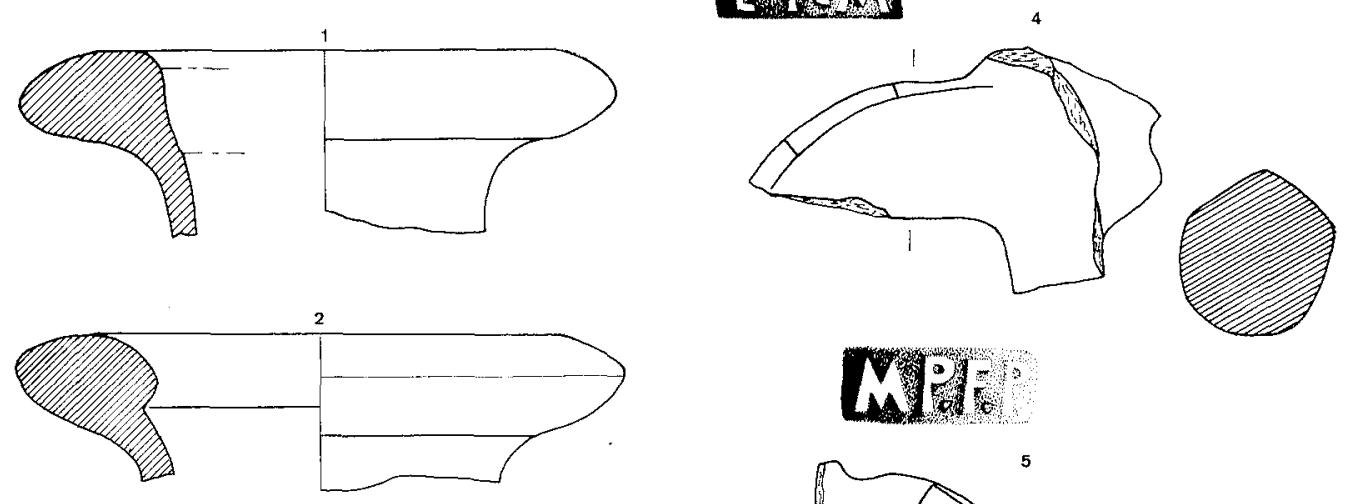

\section{CWI:}
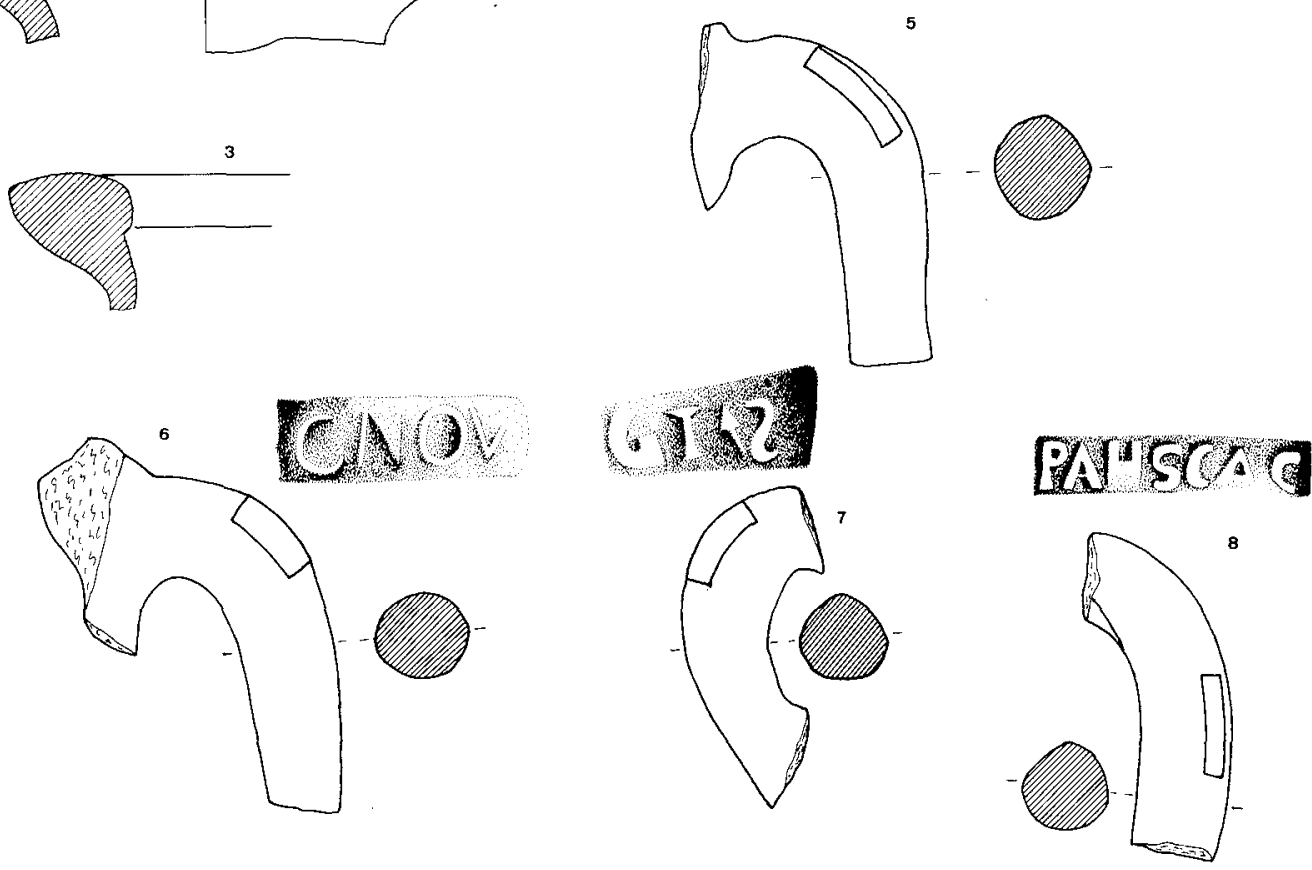

9

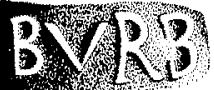

Fig. 6. Anforas olearias del tipo Dr. 20

\section{ANFORAS DE FONDO PLANO TIPO Dr. 28 (Fig. 7)}

Presentamos cinco ejemplares pertenecientes a la boca y parte superior del cuello, de alguno de los cuales ha sido posible completar el perfil hasta el hombro, teniendo en cuenta el estado de fragmentación en que se encuentra este material.

Se trata de un conjunto de ánforas de características muy homogéneas en cuanto a su morfología y a su técnica de fabricación.

De labio de doble moldura, más o menos acentuada, con una cavidad central de tres a cuatro $\mathrm{cm}$. de altura, vertical o ligeramente oblicuo. El diámetro de la boca oscila entre 14 y $17 \mathrm{~cm}$. Cuello corto y cilíndrico algo exvasado en la parte superior y asas que 

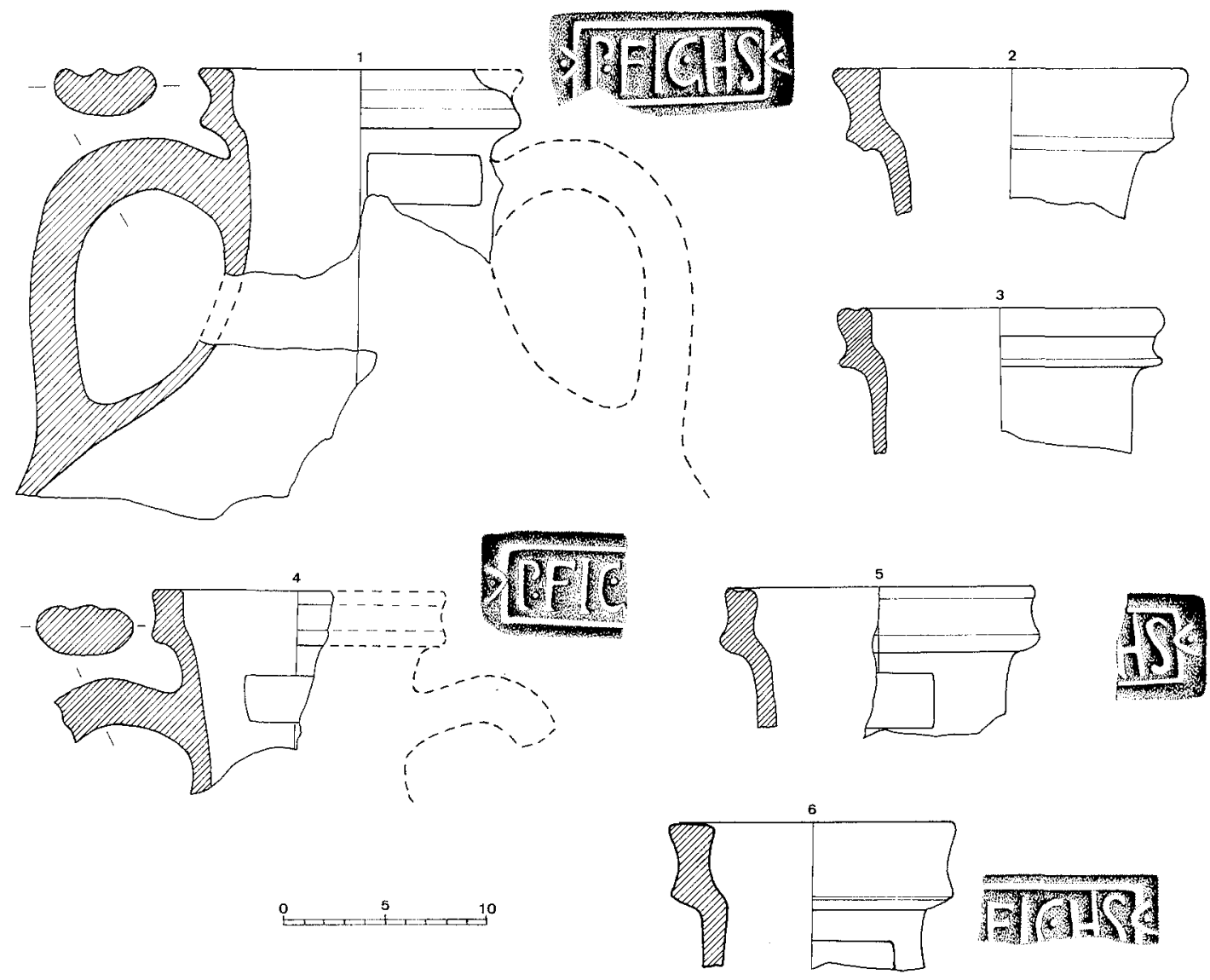

Fig. 7. Anforas del tipo Dr. 28

arrancan justo por debajo del labio con gran entrante en el cuello, las cuales se engastan a la altura del hombro formando un arco de círculo bastante regular, en forma de cinta con dos acanaladuras verticales.

En general es un ánfora de pequeñas dimensiones, de panza ovoide, con el fondo plano, aunque ambas partes no han sido identificadas como tales en nuestro yacimiento.

La pasta es porosa, muy compacta y bien cocida, de color beige-rosáceo con abundante desengrasante de puntos negros finos. En ningún caso presenta engobe.

Resulta problemático en el estado actual de la investigación definir el origen y la evolución tipológica del tipo Dr. 28. Aparecen en las excavaciones de Ventimiglia y en la nave de Albenga, datadas en los dos últimos siglos de la República (LAMBOGLIA, 1955, 265; 1952, 166), recogidas por Colls (COLLS, 1977, 46). En época augustea aparecen en Oberaden (forma Oberaden 74), con un labio de doble moldura, de cavidad central menos profunda, y asas de doble acanaladura. Las mismas características presentan en Enserune, con la marca PHILODAMUS, Haltern con la marca C. M. USSID (i) NEP (otis), parecida a la Oberaden 74 (COLLS, 1977, 46), Gabii i Vindonissa (BELTRAN, 1970, 497). La perduración de este tipo se prolonga hasta la primera mitad del siglo II (PANELLA, 1970, 156; BELTRAN, 1970, 497 y ss.).

Los ejemplares del Portus Illicitanus presentan las mismas características que los de Haltern, Tivissa y Oberaden: la misma pasta, dura, compacta y depurada, y la misma tonalidad, por lo que posiblemente se les puede atribuir un origen catalán. 
Lo más destacable de estas ánforas es la aparición, en su mayoría, de la marca P. FIG,HS, idéntica en todos los casos, en cartela rectangular, situada en el centro del cuello por debajo del labio, perfectamente legible, la cual hemos desarrollado de la manera siguiente: P (hilodamus). FIG (linae). H S (?).

\section{ANFORAS AFRICANAS (Fig. 8)}

En el curso de los siglos III y IV, tiene lugar la exportación sistemática y organizada del aceite, en las ánforas denominadas «Africanas», atribuibles al Africa Proconsular
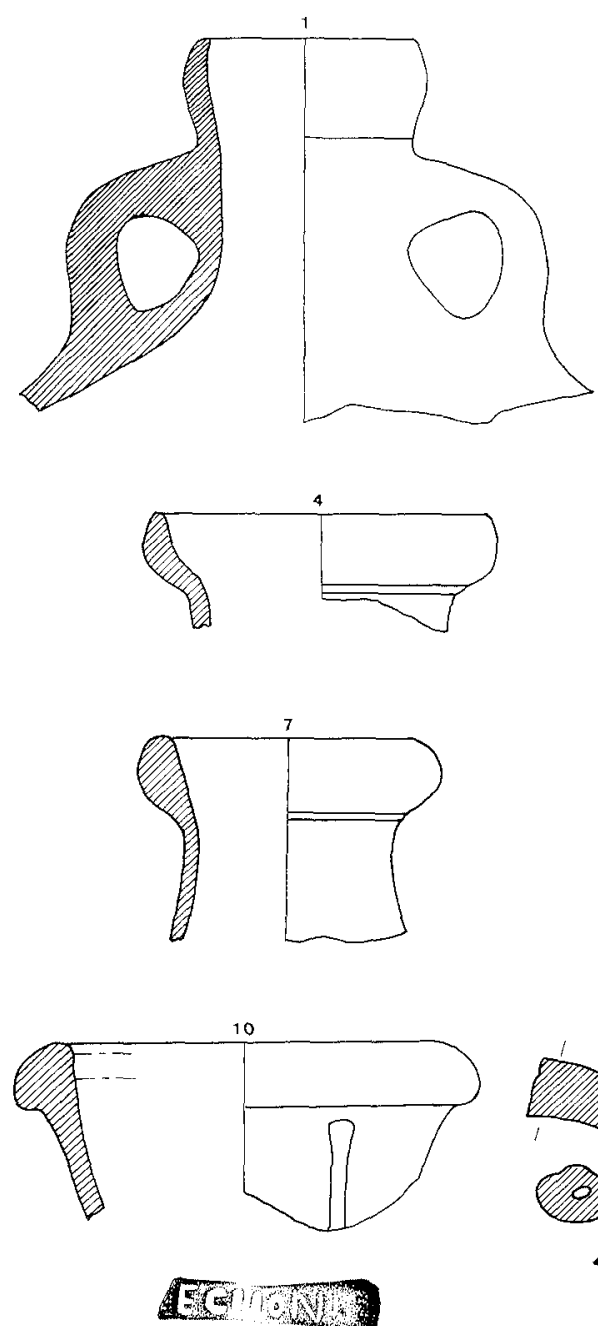

0 5 $\underbrace{10}_{10}$
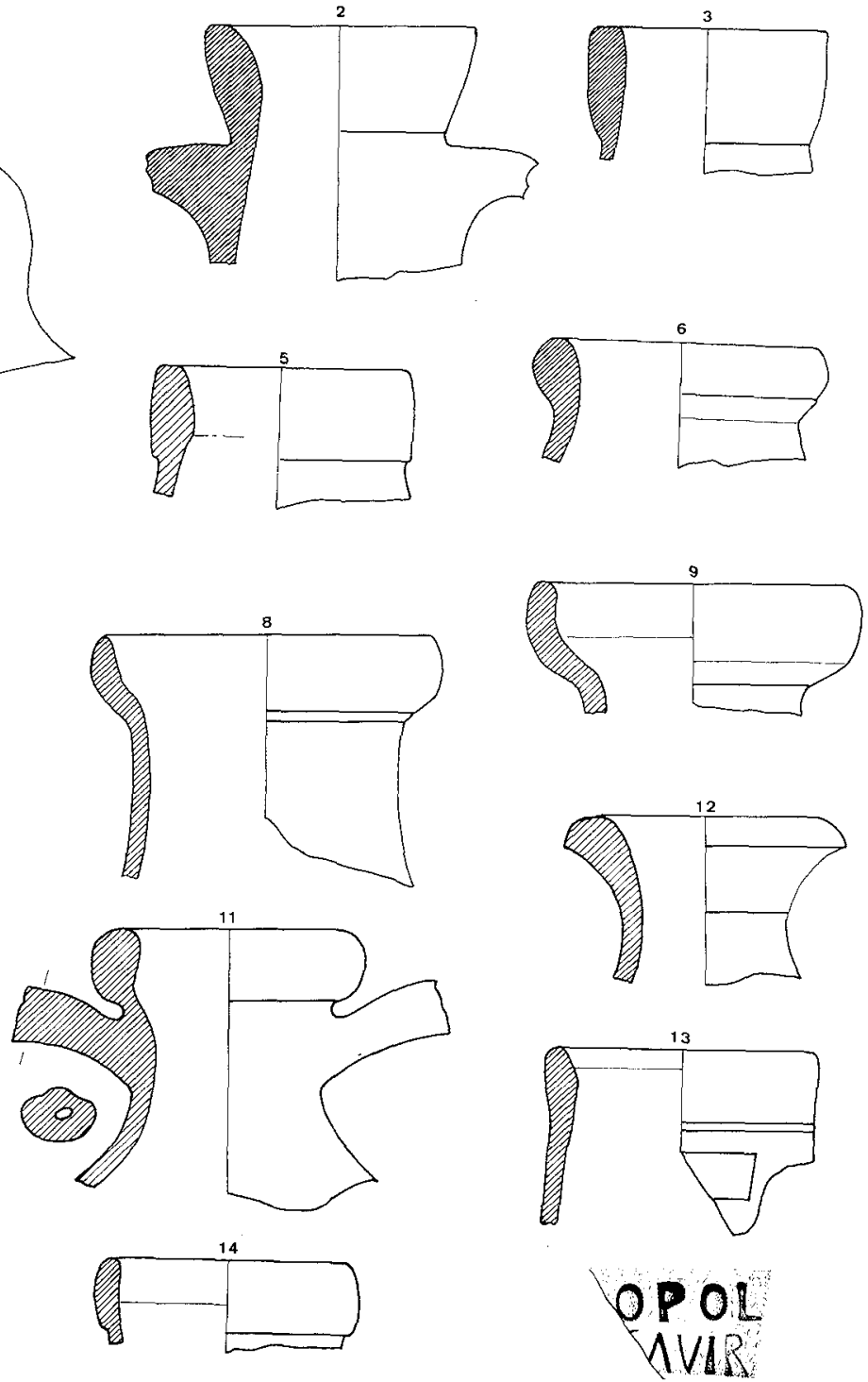

Fig. 8. Anforas africanas 
(FERNANDEZ IZQUIERDO, 1980, 141), región de gran riqueza agrícola, atestiguada en las fuentes antiguas (PANELLA, 1978, 585). Dichas ánforas, junto con la terra sigillata clara y la cerámica común africana, constituyen la documentación más significativa de la producción exportada, procedente de la Byzacena y de la Zeugitana.

Las ánforas africanas halladas en el Portus Illicitanus, tienen un claro paralelo en la «Africana II», o «Africana Grande». Se atribuyen genéricamente a este tipo todos los labios de perfil más o menos engrosado (PANELLA, 1978, 580), en ocasiones redondeado al exterior, caracterizado en su base por un ligero resalte como elemento de separación entre el labio y el cuello. La pasta es de color anaranjado en el núcleo, compacta y de aspecto rugoso, con la superficie exterior de color gris, recubierta por un engobe blanco-crema. Presenta un desengrasante de gruesas partículas blancas y abundantes puntos brillantes muy finos. Las asas arrancan por debajo del labio, en forma de cinta engrosada muy curva, con perfil en «oreja».

Aparecen dos estampillas sobre ánforas africanas (fig. 7, 10-13), impresas en cartela rectangular con caracteres incisos. En la primera se lee ..ECHONI, marca incompleta situada en sentido vertical debajo del labio. La segunda está situada en la parte central del cuello, por debajo del labio, colocada en doble línea, incompleta, en la que se lee ...OPOL / ... $\mathrm{OVIR}$.

Estas ánforas se encuentran bien documentadas durante los siglos III y IV en Ostia, aunque su fabricación comienza a finales del siglo II. En niveles datados entre el $3 .^{\circ}$ y el $5 .^{\circ}$ decenio del siglo III de «Las Termas del Nadador» de Ostia, la Africana II supera los índices de presencia de todas las ánforas atestiguadas. Tales índices tienden a aumentar en los estratos de los siglos IV y V (PANELLA, 1978, 590).

El área de difusión de este tipo se localiza en la Gallia, España, Yugoslavia, Portugal, Marruecos Occidental, Grecia (PANELLA, 1978, 590), Roma e Italia central, provenientes de la región de la Byzacena. Estos tipos, por ahora, no pueden fecharse con precisión en el Portus Illicitanus, si bien se debe señalar que nos aparecen en contextos tardíos, junto a materiales claramente datables en el siglo III. Estos datos indican que el gran auge del comercio africano se produce en la segunda mitad de dicho siglo, concretamente, como apunta Fernández Izquierdo (FERNANDEZ IZQUIERDO, 1980, 141), entre los años 250-280.

Dichos envases contenían aceite africano, que competía con el bético en los mercados de Roma y la Gallia en los años 270-280 d. C. (ZEVI y TCHERNIA, 1969, 173).

\section{ANFORAS TARDIAS, TIPO ALMAGRO 51 (Fig. 9)}

Recogemos en este apartado un grupo de ánforas pertenecientes al tipo Almagro 51 , las cuales no aparecen en la clasificación tipológica de Dressel. Dentro de este tipo, Almagro establece tres variantes: $51 \mathrm{a}, \mathrm{b}, \mathrm{c}$. Debido a la semejanza formal, incluimos nuestros ejemplares en la variante $c$.

Son ánforas de pequeño tamaño, con un diámetro medio de boca de $11 \mathrm{~cm}$., de labio engrosado, más o menos redondeado al exterior y de sección triangular. Cuello corto, troncocónico, que se une al hombro mediante una curva poco marcada, y asas aplastadas en forma de cinta, de sección oval. En algunos ejemplares se observan tres líneas incisas alrededor del cuello, lo que consideramos pueda tratarse de una imitación de dicha forma. (Fig. 9, núms. 3-4.)

La pasta oscila entre el color marrón al rojo anaranjado, porosa, laminosa, de textura basta con numeroso desengrasante de mica dorada. La pared exterior se halla recubierta por un engobe blanquecino de tacto harinoso, que salta con facilidad. La superficie interior presenta estrías, producidas por el torno. 

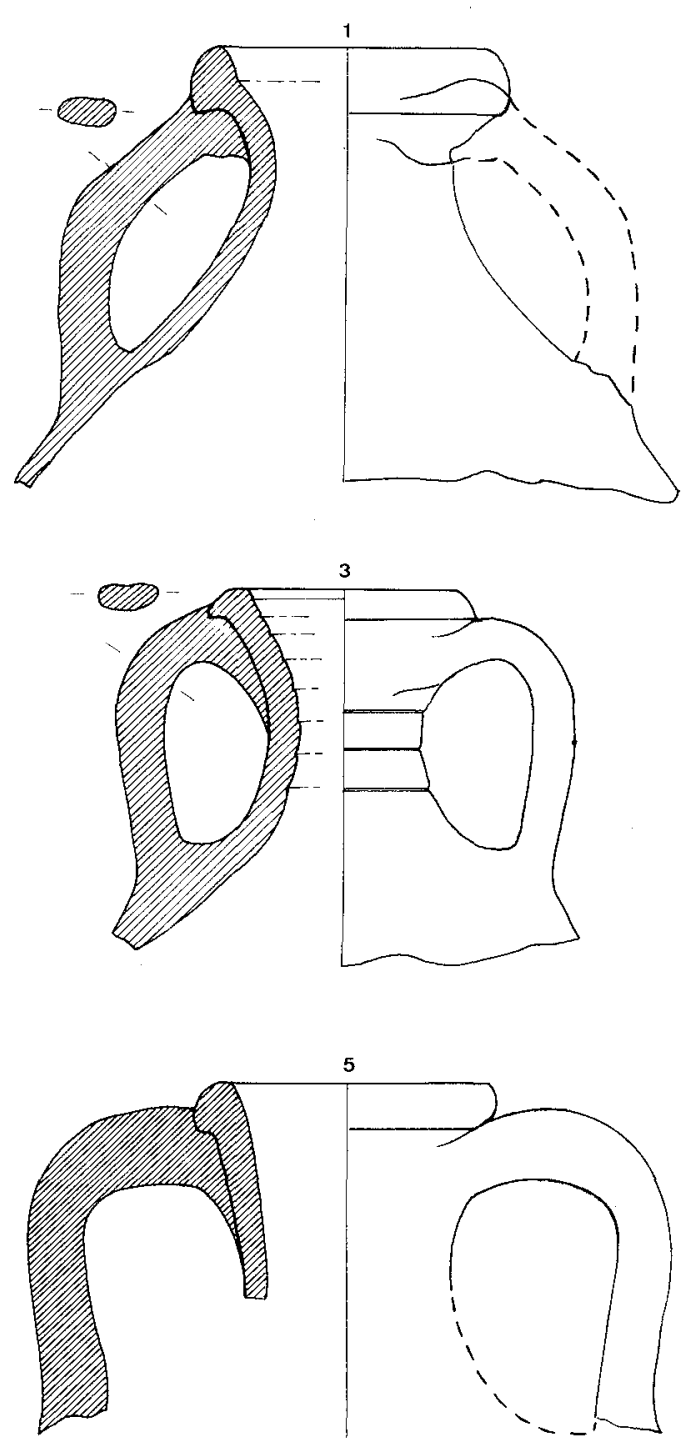
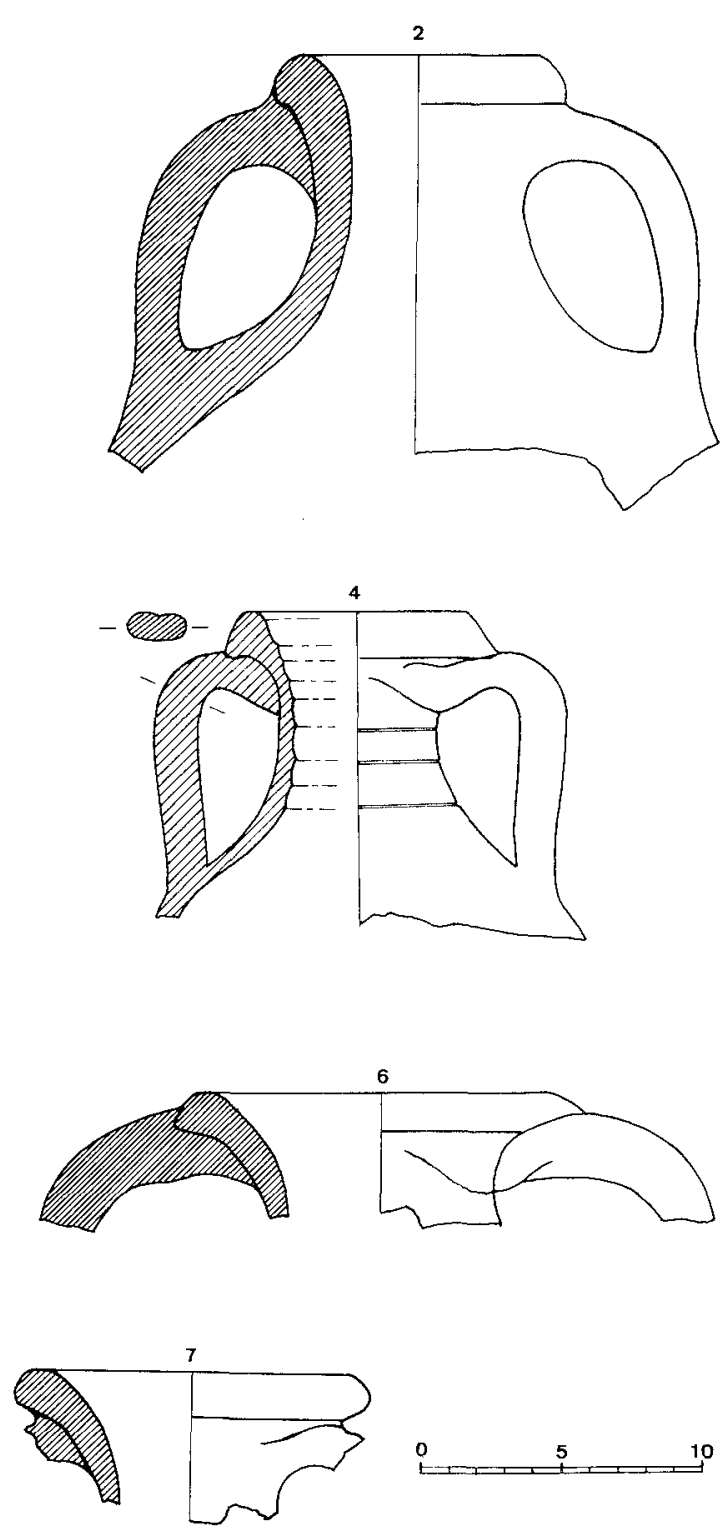

Fig. 9. Anforas del tipo Almagro 51

Esta variante Almagro $51 \mathrm{c}$, aparece en Ampurias en la inhumación Estruch, con el n. ${ }^{\circ} 21$ (ALMAGRO, 1955, 207, fig. 289), en la Necrópolis de les Foies de Valencia, en San Fructuoso de Tarragona, San Pedro del Pinatar, Cartagena (Murcia) y Almería, recogidas por Beltrán (BELTRAN, 1970, 543) y en la Necrópolis de la Boatella (Valencia), recogidas por Fernández Izquierdo (4), datable a fines del siglo III.

Esta variante c se considera la más tardía del tipo Almagro 51 al no aparecer en la inhumación del Castellet, donde este tipo es muy abundante. Dicha necrópolis es considerada por Almagro anterior a la de Estruch, datable en el siglo IV, y establece la datación de este tipo en la transición del siglo III al IV (ALMAGRO, 1955, 307). Aunque no

(4) Noticia oral, de A. Fernández Izquierdo, recogida después de la redacción de este trabajo. 
se puede precisar con exactitud la cronología de dichos envases, consideramos un dato a tener en cuenta su presencia en el Portus Illicitanus, junto a ánforas africanas, tipo II de Ostia, fechables entre los siglos III y IV.

Estos recipientes, posteriormente, fueron reutilizados para enterramientos en necrópolis de inhumación, como hemos mencionado anteriormente.

\section{ANFORAS INDETERMINADAS (Fig. 10)}

En nuestra clasificación hemos recogido tres ejemplares, hasta ahora no identificados en las tipologías consultadas. Proceden del relleno de una balsa, por lo que carecen de contexto arqueológico, si bien por su aspecto general nos inclinamos a considerarlas dentro de una época tardía.

Presentan un diámetro de boca reducido, cuello corto y estrecho, asas redondeadas de aspecto macizo, paredes gruesas y en general pequeñas dimensiones.

La pasta suele ser en todas ellas de color marrón claro, mal cocida, poco decantada, porosa, con abundante desengrasante de gruesos granos blancos y negros, y de factura muy tosca. En uno de estos recipientes (fig. 9 , n. ${ }^{\circ}$ ) se observan estrías en el interior de la pared.

Próximos y futuros hallazgos, quizá aporten nueva luz a estos datos.
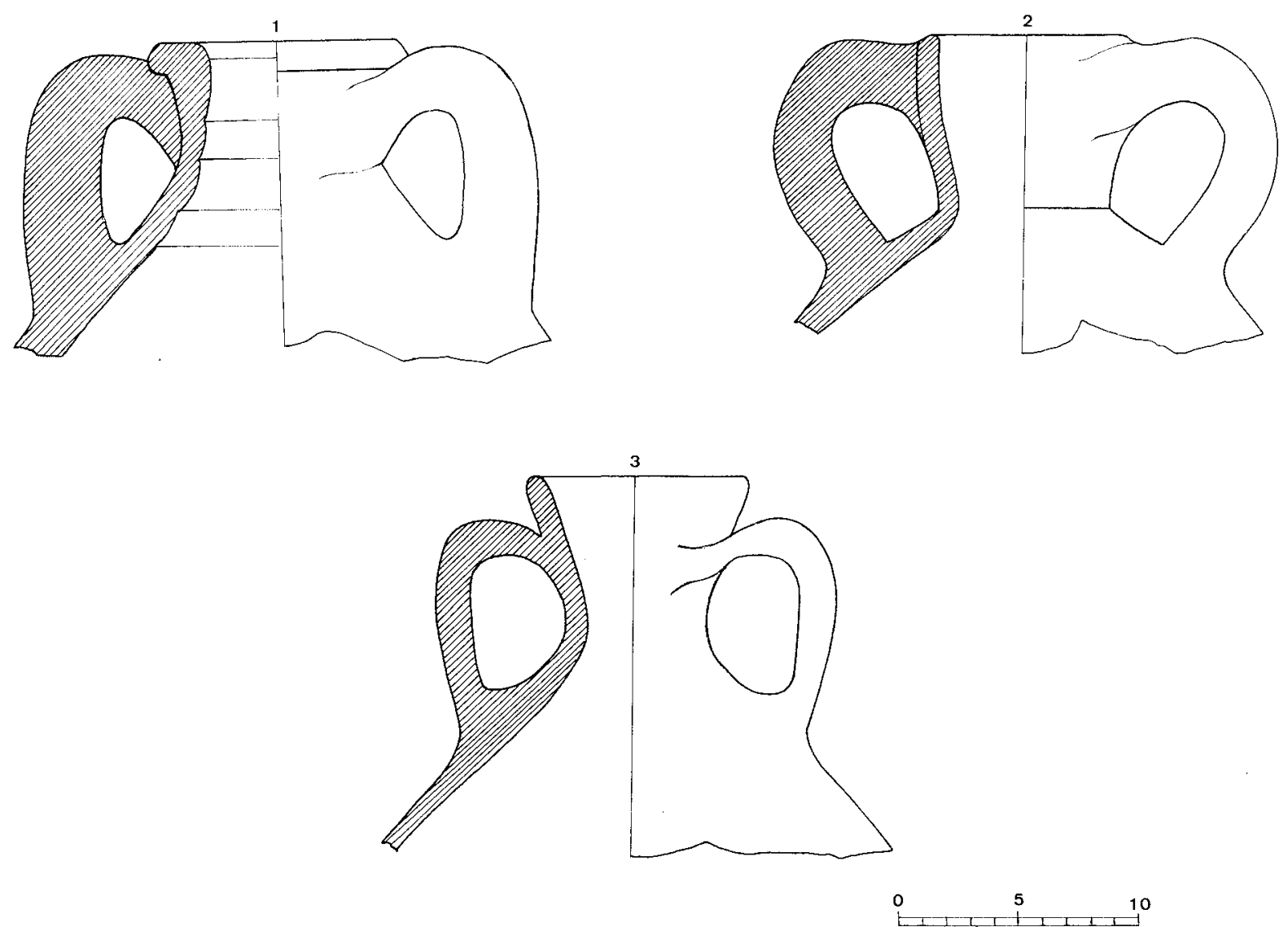

Fig. 10. Anforas tardías 


\section{CONCLUSIONES}

La gran cantidad de ánforas de diversas tipologías halladas en el Portus Illicitanus, supone una muestra del intenso comercio marítimo desarrollado en dicho puerto, en época romana, por espacio de más de cinco siglos. Los estratos republicanos se hallan aún por excavar. El material anfórico perteneciente a esta época aportará nuevos datos sobre los comienzos del comercio de esta zona.

Se observa una primera etapa, que abarcaría desde el cambio de era hasta la segunda mitad del siglo II, un neto predominio de los productos hispánicos, polarizándose los mercados entre la provincia tarraconense, atestiguada por la presencia de ánforas vinarias del tipo Dr. 2-4 y Dr. 28, y la Bética, con el hallazgo de un gran volumen de ánforas de salazones del tipo Dr. 7-11 y, en bastante menor proporción, de la olearia tipo Dr. 20.

Un dato de gran interés para el estado actual de nuestros conocimientos, se deriva de la afluencia al Portus Illicitanus de los productos más comercializados en el Mediterráneo a comienzos del Imperio: vino, envasado en ánforas de fabricación tarraconense, en su mayoría, y salsas de pescado y aceite, procedentes del Sur peninsular.

La presencia de las ánforas Dr. 2-4, viene a demostrar la importancia que el vino tenía en estos siglos, como producto comercializado a gran escala, dentro del mundo romano, manteniéndose en el mercado desde comienzos del reinado de Augusto hasta la segunda mitad del siglo II.

El tipo predominante en el Portus Illicitanus en época altoimperial es el ánfora de salazones Dr. 7-11, de origen bético, en la cual se inicia la exportación de salazones andaluces, los cuales se mantienen en uso desde época augustea hasta finales del siglo II, y tal vez algunos decenios más, con un gran número de variantes y una amplia difusión en todo el litoral mediterráneo y fuera de la Península. Dentro de esta misma familia, contamos con algunos ejemplares del tipo Dr. 8, que por su morfología se los puede incluir en un grupo diferenciado de los demás.

Al igual que en el resto de nuestra costa, queda constatada la escasa presencia del tipo Dr. 20, dedicado al transporte del aceite, reduciéndose a escasos fragmentos y algunas marcas en niveles altoimperiales. No ocurre así con el aceite africano, que a partir de la segunda mitad del siglo III, llega masivamente al Portus Illicitanus en ánforas de la forma «Africana II», también denominada por Zevi «Africana Grande», cuya presencia subsiste hasta finales del siglo IV. En lo referente a otros productos de importación africana se observa el mismo fenómeno, ya que aparecen grandes cantidades de sigillatas claras en todas sus variantes, platos de borde ahumado, cuencos de borde aplicado, cazuelas de fondo estriado, etc. La profusión de ánforas africanas, junto al resto de los productos mencionados, es un hecho que demuestra la gran demanda comercial de este momento. En niveles tardíos de finales del siglo III y comienzos del IV, las ánforas africanas superan los índices de presencia de todas las demás atestiguadas. La preponderancia cuantitativa de productos africanos en el Portus Illicitanus en los siglos III y IV se debe, sin duda, a la consecuencia de un proceso de explotación sistemática de los recursos agrícolas de la Tunisia, potenciado por los Severos en un intento conseguido de impulsar la producción de la oleicultura africana.

La problemática relativa al comercio del aceite africano, dentro de un contexto arqueológico, ha sido correctamente analizada por C. Panella (PANELLA, 1978) en las excavaciones de Ostia, lo cual constituye una síntesis de las cuestiones desarrolladas en torno a estos temas.

Otros tipos encontrados en el Portus Illicitanus son las Dr. 28, de posible origen catalán, la Almagro 51,y otras formas tardías, hasta ahora no identificadas en las tipolo- 
gías consultadas al réspecto, por lo que puede tratarse de producciones locales, fabricadas dentro de un área geográfica próxima al Portus Illicitanus.

Esta gran variedad tipológica presupone un comercio marítimo ininterrumpido desde el cambio de era hasta el siglo $\mathrm{V}$, y tal vez algunos decenios más. Se observan dos etapas de auge comercial atestiguadas por el número de ánforas y otros productos importados. La primera podría situarse desde la época de Augusto hasta fines del siglo II. Se produce una cierta decadencia en la primera mitad del siglo III, puesto que se aprecia un descenso de las importaciones. Una segunda etapa de resurgimento comercial y económico tiene lugar en la segunda mitad del siglo III, con el incremento del comercio con el Norte de Africa.

La extensa cronología de las ánforas objeto del presente trabajo, nos permite deducir que el Portus Illicitanus inicia el proceso de romanización en una época muy antigua, posiblemente antes del cambio de era y su actividad comercial perdura hasta bien entrado el siglo $\mathrm{V}$.

Cuando el estudio del resto de materiales esté concluido y próximas excavaciones proporcionen nuevos hallazgos, tendremos más elementos de juicio para dar como definitivas muchas de las conclusiones que aquí hemos expuesto, y que por el momento sólo tienen carácter profesional.

Alicante, abril de 1984 


\section{BIBLIOGRAFIA}

ALMAGRO, Martín, 1955, «Las Necrópolis de Ampurias», Ampurias, vol. I-II, Barcelona.

ARANEGUI GASCO, Carmen, 1978, «Anotaciones sobre las ánforas del nivel de relleno del Grau Vell, Sagunto (Valencia)», SAGUNTUM, 13, Papeles del Laboratorio de Arqueología de Valencia, Universidad de Valencia.

- 1981, «La producción de ánforas romanas en el País Valenciano, estado de la cuestión», Archivo de Prehistoria Levantina, vol. XVI, Valencia.

BELTRAN LLORIS, Miguel, 1970, Las ánforas romanas en España, Monografias arqueológicas, 7, Zaragoza.

- 1977, «Problemas de la morfología y del concepto histórico-geográfico que recubre la noción tipo. Aportaciones a la tipología de las ánforas béticas», Méthodes Classiques et Méthodes Formelles dans l'Etude des Amphores, Ecole Française de Rome.

CALLENDER, M. H., 1965, Roman amphorae, Oxford University Press, London.

COLLS, Dalí, 1977, «L'Epave de Port-Vendres II et le commerce de la Bètique a l'époque de Claude», Editions du Centre National de la Recherche Scientifique, París. Archeonautica I.

ENGUIX, Rosa, y ARANEGUI, Carmen, 1977, El taller de ánforas romanas de Oliva (Valencia), Servicio de Investigación Prehistórica, Serie de Trabajos Varios, 54, Valencia.

FERNANDEZ IZQUIERDO, Asunción, 1980, «Estudio de los restos arqueológicos submarinos en las costas de Castellón», Cuadernos de Prehistoria y Arqueología Castellonenses, Diputación Provincial de Castellón de la Plana, Castellón de la Plana.

LAMBOGliA, Nino, 1952, «La Nave Romana di Albenga», Riv. Stud. Liguri, XVIII, Bordighera.

- 1955, «Sulla cronologia della anfore romane di etá republicana», Riv. Stud. Liguri, XXI, Bordighera.

LAUBENHEINER, F., y WINDERMANN, F., 1977, «L'atelier de Corneilhan (Hérault), Tipologie et analyse», Colloque Français d'Archeometrie, Rennes. (Citado por Aranegui, 1978.)

LUSUARDI, Silia, 1977, «Appunti su alcuni tipi di anfore lunensi», Méthodes Classiques et Méthodes Formelles dans l'Etude des Amphores, Ecole Française de Rome.

NOLLA, José M. ${ }^{a}, 1974-75$, «Las ánforas romanas de Ampurias», Ampurias, 36, Barcelona.

PANELlA, Clementina, 1970, "Le Terme del Nuotatore», Ostia II, Estudii Miscellanei, 16, Roma.

- 1972, "Anotacioni in margine alle stratigrafie delle Terme Ostiensi del Nuotatore», Recherches sur les amphores romaines, Ecole Française de Rome, Rome.

1973, «Appunti su un gruppo di anfore della prima, media e tarda etá imperiale (Secoli del I-V d. C.)», Ostia III, Estudii Miscellanei, 21, Rome.

Producción y comercio del aceite en la antigüedad, 1980, Primer Congreso Internacional, Universidad Complutense, Madrid.

REMESAL RODRIGUEZ, J., 1977-78, «Economía oleícola bética: nuevas formas de análisis», Archivo Español de Arqueología, 50-51, Madrid.

SANCHEZ FERNANDEZ, M. ${ }^{a}$ José, 1983, «La cerámica común romana del Portus Illicitanus», Lucentum, II, Universidad de Alicante, Alicante.

TCHERNIA, A., y ZEVI, F., 1971, «Amphores vinaires de Tarraconainse et leur exportation au début de l'Empire», Archivo Español de Arqueología, 44, Madrid.

- 1972, «Amphores vinaires de Campanie et de Tarraconainse a Ostie», Recherches sur les amphores romaines, Ecole Française de Rome, París.

TCHERNIA, A., 1977, «Note sur le matériel recuilli dans les fouilles d'un atelier d'amphores à Velaux (Bouches-du-Rhône)», Méthodes Classiques et Méthodes Classiques dans l'Etude des Amphores, Ecole Française de Rome.

ZEVI, F., 1966, «Appunti sulle anfore romane», Archeologia Classica, 18, 2, Roma. (Citado por Enguix y Aranegui, 1977).

ZEVI, F., y TCHERNIA, A., 1969, «Amphores de Byzacène au Bas Empire», Antiquités Africaines, 3, Centre National de la Recherche Scientifique, París. 